\title{
GRÜNWALD-LETNIKOV FRACTIONAL OPERATORS: FROM PAST TO PRESENT
}

\author{
Ferhan M. Atici* ${ }^{*}$ Samuel Chang And Jagan Jonnalagadda
}

\begin{abstract}
In this paper, we establish a connection between the well-known Grünwald-Letnikov fractional operators which were defined in the mid-1800s and the recently defined fractional $h$ discrete operators. We prove that the Mittag-Leffler function of the Riemann-Liouville fractional calculus in continuous time is the limit of the Mittag-Leffler type function in fractional $h$-discrete calculus in discrete time when $h$ approaches zero. In our study, we only focus on the backward difference operators which are also known as discrete nabla operators.
\end{abstract}

Mathematics subject classification (2020): 39A12, 39A70, 26 A33.

Keywords and phrases: Grünwald-Letnikov operators, Mittag-Leffler function, nabla operator, fractional $h$-discrete calculus.

\section{REFERENCES}

[1] P. T. Anh, P. Jurgas, M. Niezabitows Ki And S. Siegmund, Variation of constant formulas of linear autonomous Grünwald-Letnikov-type fractional difference equations, International Conference of Numerical Analysis and Applied Mathematics (ICNAAM 2018), AIP Conf. Proc., 2116, (2019), $1-4$.

[2] F. M. ATici, K. Dadashova And J. Jonnalagadda, Linear fractional order $h$-difference equations, Special Issue Honoring Professor Johnny Henderson, Int. J. Difference Equ., 15 (2), (2020), 281-300.

[3] F. M. Atici And P. W. Eloe, Discrete fractional calculus with the nabla operator, Electron. J. Qual. Theory Differ. Equ., Special Edition I (3), (2009), 12 pp.

[4] F. M. Atici, N. Nguyen, K. Dadashova, S. Pedersen And G. Koch, Pharmacokinetics and Pharmacodynamics Models of Tumor Growth and Anticancer Effects in Discrete Time, Comput. Math. Biophys., 8 (2020), 114-125.

[5] N. R. O. Bastos, R. A. C. Ferreira And D. F. M. Torres, Discrete-time fractional variational problems, Signal Processing, 91 (3), (2011), 513-524.

[6] M. Bohner And A. C. Peterson, Advances in Dynamic Equations on Time Scales, Birkhauser Boston, MA, (2003).

[7] M. Bohner and A. C. Peterson, Dynamic Equations on Time Scales, Birkhauser, Basel, (2001).

[8] J. B. Diaz And T. J. Osler, Differences of fractional order, Math. Comp., 28, (1974), 185-202.

[9] Rui A. C. FERreira AND D. F. M. Torres, Fractional h-difference equations arising from the calculus of variations, Appl. Anal. Discrete Math., 5 (1), (2011), 110-121.

[10] M. FIELD, Essential Real Analysis, Springer International Publishing, AG, (2017).

[11] C. Goodrich And A. C. Peterson, Discrete Fractional Calculus, Springer, Cham, (2015).

[12] A. K. GRÜNWALD, Über "begrenzte” Derivetionen und deren Anwendung, Z. Angew. Math. Phys. 12 (1867), 441-480.

[13] B. JiA, F. Du, L. ERbe AND A. Peterson, Asymptotic behavior of nabla half order $h$-difference equations, J. Appl. Anal. Comput., 8 (6), (2018), 1707-1726.

[14] V. T. Kim And R. Gorenflo, The Grünwald-Letnikov difference operator and regularization of the Weyl fractional differentiation, Z. Anal. Anwendungen, 13 (3), (1994), 537-545.

[15] A. V. Letnikov, Theory of differentiation with an arbitrary index, Mat. Sh. 3 (1868), 1-66, (in Russian). 
[16] X. Liu, A. C. Peterson, B. JiA And L. ERBe, A generalized h-fractional Gronwall's inequality and its applications for nonlinear h-fractional difference systems with 'maxima', J. Difference Equ. Appl., 25 (6), (2019), 815-836.

[17] D. Mozyrska And E. GiRejKo, Overview of fractional h-difference operators, Operator Theory: Advances and Applications, 229, (2013), 247-262.

[18] D. Mozyrs Ka, E. GirejKo AND M. Wyrwas, Comparison of $h$-difference fractional operators, Advances in the Theory and Applications of Non-integer Order Systems, Lect. Notes Electr. Eng., Springer, Cham, 257, (2013), 191-197.

[19] D. MOZYRSKA, E. GIREJKO AND M. WYRWAS, Local observability and controllability of nonlinear discrete-time fractional order systems based on their linearisation, Internat. J. Systems Sci., 48 (4), (2017), 788-794.

[20] D. Mozyrs Ka AND P. OstalCZYK, Variable-, fractional-order Grünwald-Letnikov backward difference selected properties, 2016 39th International Conference on Telecommunications and Signal Processing (TSP), (2016), 634-637.

[21] D. Mozyrska, E. PAWluszewicz, Local controllability of nonlinear discrete-time fractional order systems, Bull. Pol. Ac.: Tech., 61 (1) (2013), 251-256.

[22] P. OstalczYK, Discrete Fractional Calculus. Applications in Control and Image Processing, World Scientific, 2015.

[23] M. D. Ortigueira And F. Coito, From differences to derivatives, Fract. Calc. Appl. Anal., 7 (4), (2004), 459-471.

[24] P. W. OstalcZYK, A note on the Grünwald-Letnikov fractional-order backward-difference, Physica Scripta, 136, (2009).

[25] P. Oziablo, D. Mozyrska and M. Wyrwas, A digital PID controller based on GrünwaldLetnikov fractional, variable-order operator, 2019 24th International Conference on Methods and Models in Automation and Robotics (MMAR), (2019), 460-465.

[26] I. Podlubny, Fractional Differential Equations, Academic Press, San Diego, (1999).

[27] S. G. Samko, A. A. Kilbas, O. I. Manchev, Fractional Integral and Derivatives: Theory and Applications, Gordon and Breach, Yverdon, (1993).

[28] R. Scherer, S. L. KAlla, Y. TANG AND J. Huang, The Grünwald-Letnikov method for fractional differential equations, Comput. Math. Appl., 62 (3), (2011), 902-917.

[29] I. SUWAN, S. OWIES AND T. ABDELJAWAD, Monotonicity results for h-discrete fractional operators and application, Adv. Difference Equ., 207, (2018), 1-17.

[30] V. E. TARASOV, Fractional-order difference equations for physical lattices and some applications, J. Math. Phys., 56 (10), (2015), 19 pp.

[31] Y. WeI, W. YIN, Y. ZHAO AND Y. WANG, A new insight into the Grünwald-Letnikov discrete fractional calculus, ASME. J. Comput. Nonlinear Dynam., 14 (4), (2019), 1-5.

[32] Y. WEI, W. YIN, Y. ZHAO AND Y. WANG, Lyapunov functions for nabla discrete fractional order systems, ISA transactions, 88, (2019), 82-90.

[33] M. Wyrwas, E. PaWluszewiCZ AND E. GiReJ Ko, Stability of nonlinear h-difference systems with $n$ fractional orders, Kybernetika (Prague), 51 (1), (2015), 112-136. 